\title{
Curriculum Development of College English Follow- up Courses Based on Need Analysis
}

\author{
Lili Sun \\ College English Teaching Department \\ Zaozhuang University \\ Zaozhuang, China
}

\begin{abstract}
This study conducted a questionnaire survey on non-English Majors in Zao Zhuang University. The purpose of the survey is to understand students' needs for improving English skills, subsequent elective courses, learning objectives and goals after passing College English Test Band Four. Based on the analysis of the survey results, the design, teaching module, teaching material and resources of College English follow-up elective courses based on "demand analysis" were discussed.
\end{abstract}

Keywords-need analysis; follow-up courses; elective courses; college English

\section{INTRODUCTION}

With the advent of the transition period of College English teaching reform, the teaching of special purpose (ESP) based on learners' specific needs will become a direction of College English teaching reform. ESP teaching as a bridge to link College English teaching and senior grade (or professional English), is playing an increasingly prominent role in the reform of College English Teaching in local universities. The discussion and practice of need analysis abroad has been over 30 years ago. Foreign scholars in different periods have different definitions for needs analysis of foreign language, and the connotation of them is enriched with the progress of the times. Goal oriented requirements (goal-oriented) (Widdowson, 1981), the analysis of learner centered demand (learner-centred analysis) and the target situation analysis is the core of the demand (target-centred analysis) (Bloor, 1986), the target needs and learning needs (HutchinsonWaters, 1987), the objective and subjective demand (Brindley, 1989). Hutchinson \& Water have more mature achievements in both empirical and theoretical research, and they think that demand can be divided into target demand and learning demand. Objective needs are learners' knowledge and skills that they must learn in order to make good use of them. Learning needs refer to what learners need to learn.

\section{LITERATURE REVIEW}

In 2007, the Ministry of Education issued the "College English curriculum requirements". It is clear that colleges and universities should combine the compulsory courses and elective courses according to the actual situation, and design their respective College English curriculum system. The academic researchers have already discussed the extended course system of College English. Yang Zhizhong (1999) and Xia Jimei (2002) put forward the necessity of further College English teaching principles from the theory; Wang Binhua, Liu Hui (2003), Zheng Yuqi (2006), Yang Yulan (2010) study from the perspectives of empirical investigation of learning needs, curriculum, teaching methods, teaching materials and teachers etc.. Xie Jiguang (2003) and Huang Bing (2009) and other scholars specifically analyzed Followup College English curriculum requirements, development and reform direction of the needs analysis theory research of College English Teaching for science students and minority students. Many universities have carried out the reform of College English curriculum, increasing college English Teaching in the subsequent stages. Take Tsinghua University for example, it has realized the connection between the basic stage and the application improvement stage since 2001. It not only provides a basic course for college freshmen, but also offers practical courses such as writing, translation and oral English, so that students can choose according to their abilities. In addition, some other universities in China have offered elective courses such as advanced English and science English for students who have passed College English Test Band Four, but also in the fifth semester and the sixth semester.

Although the previous research on need analysis has become increasingly prominent. However, in the process of foreign language teaching in China, the demand analysis of foreign language teaching has always been a link without due attention, and the corresponding theoretical research is also relatively weak(Shu Dingfang, Su Yan Chen, 2009). Shu Dingfang puts forward nine problems in College English teaching, second of which are "lack of demand analysis" and need to strengthen demand analysis. At present, the domestic research on the need of College English follow-up courses in local universities is still at the initial stage, so it is necessary to further explore how to build a scientific and reasonable follow-up curriculum system of College English which is in line with the characteristics of local universities.

With the continuous improvement of the general English teaching level, a considerable number of non- English majors can pass the National College English test four or six. The overall improvement of students' English level is an indisputable fact. 
In 2007, the Ministry of Education announced "The Requirements for College English Teaching". It put forward that: according to the actual situation, colleges and universities should design their respective College English curriculum system according to the requirements of the curriculum and the goal of College English teaching. Colleges and universities should combine compulsory courses with elective courses such as integrated English language skills, language application, language and culture to ensure that different levels of students are fully trained and improved in English application ability.

Therefore, some schools begin to set up College English elective courses to meet the English learning needs of students who have passed the level four of College English. After several years of exploration, courses are increasingly diversified, from single language skills course and exam guidance course to a series of ESP courses that are more close to social and cultural needs. Follow-up courses of many schools are no longer taken as elective courses, but are formally incorporated into the College English course system as a course for the application of College English.

\section{THEORETICAL BASIS FOR THE FOLLOW-UP COURSES OF COLLEGE ENGLISH}

The follow-up College English courses based on the need analysis refer to the elective courses provided for nonEnglish majors who have passed the college English level test four or six to continue to follow their interest or need to learn. This kind of English teaching is a multidimensional teaching concept, which is based on the theory of contentbased teaching and demand analysis theories.

\section{A. Content-based Instruction}

Content-based Instruction (CBI) is referred to a teaching method based on subject content to learn second language. This teaching method establishes language teaching on a subject or subject matter combines language learning with subject knowledge learning to improve students' knowledge level and cognitive ability and to promote their language ability development. The most obvious feature of the content-based teaching method is to develop and improve the ability of language application by learning the knowledge of the subject. In the course of content-based teaching, the learners choose the subject of interest according to their own learning needs and the learning materials they are exposed to. It's all the real language material. These materials provide learners with a large number of comprehensible language input, and explore new subjects and knowledge, which not only satisfy learners' specific learning needs, but also improve their language application.

\section{B. Need Analysis}

Need analysis is an essential step for the curriculum design. The analysis of social need and learning need is necessary for a reasonable college English course.

1) Social demand: Social demand refers to the social demand for foreign language ability. With increasingly frequent international exchange, demands for talent are much higher. They not only need to have a solid foundation of professional knowledge, but also are able to communicate with flexible languages, especially with English. And different professionals have different professional demand for English ability. Research oriented majors need to be able to understand foreign information. At any time, they are always aware of the development of foreign countries in the same field they are engaged in. People need to pay more attention to English ability in reading and writing. And for social-type profession, it requires the practitioners to be able to communicate fluently and freely with others.

The main emphasis is placed on the ability of listening and speaking in English. According to the different needs of the society, high schools need to develop different levels of professionals for different needs. So only with a clear understanding of the needs of the society, can the setting of the curriculum be established scientifically and rationally? On the basis of the training, the students will be able to better serve all sectors of the society.

2) Learner demand: Students are the main body of learning, so the modern educational concept advocates "human beings", "student centered", emphasizing the needs of the students. Students' demand is mainly divided into professional demand, target demand, psychological and emotional demand. First of all, students from different majors have different requirements for the learning of English knowledge and the English ability. For example, students of legal profession need to learn English in ordinary English teaching classes and they also need to know the English knowledge related to their major. Second, students in the same college have different plans for their future. Some students want to take further education after graduation; some students want to go to work after graduation. The difference of their future plan determines that the need for English learning is not the same. For postgraduate entrance examination, students are required to be able to provide a deeper and more extensive knowledge of English in order to get good results in the test and at the same time lay a solid foundation. And for the students who will take a job after graduation, They need to be trained more practical English to meet the demand of English ability in future jobs. They can also manage to handle the relationship between study and work. English teaching helps students to meet the requirement of English ability. There are great differences between students. Different students have different interests, motivations and different basis of the same English language, so teachers should take full account of the emotional causes of the students. In order to satisfy different learners from different English ability levels, school should set up English knowledge in different aspects to meet their needs.

Schools can set up a general English, for those students who have difficulties in grammar, vocabulary, pronunciation, writing and learning methods of the students to make up for the lack of communicative competence of students' English. 
With the introduction of specific occupation or related disciplines of English, schools can provide different courses such as western society and culture, intercultural communication, senior English reading, writing, translation and tourism according to the specific needs and objectives of the curriculum of students. The purpose of setting up the courses is to train students to use English to carry out the work of communication in a certain working environment and the professional ability of using English.

\section{RESEARCH METHODS AND DESIGN}

At present, the demand analysis is very important for College English Teaching in China. It is not only the premise of the school set syllabus according to the actual situation, but also the evaluation of a diagnostic procedure for the implementation and improvement of the teaching plan. For a college English teacher and some teaching responsible departments, only by doing well the needs analysis can we fully understand the needs of students in all aspects of learning process. And then schools can formulate practical teaching objectives and teaching plans, and make specific analysis of specific problems.

Based on this consideration, the author makes a research of the learning need of students through questionnaires and interviews. The subjects are total 500 non-English major undergraduates from grade two and three who have passed CET4(College English Test 4). And the results were analyzed, aimed at providing a scientific standard for college English teaching objectives and teaching methods.

\section{A. Purpose and Content of Questionnaire Survey}

A questionnaire was designed for the students and teachers in our school. The survey can get the present situation of College English teaching for students who have passed the level four of College English. The questions are designed from the following aspects: learning motivation, course setting, teaching method and management mode in the continued course. Investigations have been carried out in all aspects. The main questions include: (1) whether or not extended courses need to be opened (2) the understanding of teaching and learning in the follow-up course of College English (3) What actual needs are needed (4) The students' understanding of teaching objectives of current college general English (EGP) (5)The total number of school hours and teaching materials for EGP.

\section{B. Method of Investigation}

The questionnaire was conducted in April 2017. It has mastered the specific people of each class who have passed the four level of College English. Through the survey, we know the need for follow-up courses after college English test four. And in June, College English teachers were enrolled. Another questionnaire survey was conducted to understand the teachers' views and ideas on the follow-up course.

\section{The Description and Analysis of the Statistical Results}

The survey of the questionnaire is the juniors and seniors of our school who have passed the college English test for level four or six. A total of 800 questionnaires were issued and the teachers' Questionnaire 40 copies. 684 copies of the students' questionnaire were collected, and the number of class four was 401 . The number of people through six levels was 283, and 39questionnaires were collected from the teachers.

Question 1: Which subsequent courses / type (s) do you want?

\section{A language enhancement classes \\ B practical English class \\ $\mathrm{C}$ language and culture \\ D special-purpose English class}

About the needs of courses, $51 \%$ of the students chose "courses combined with professional English", followed by "ordinary English as a required". At the same time, professional English is set up (25.39\%). It shows that most students are aware of the importance of their specialties. But the importance of ordinary English and their English levels, they are not yet able to skip the general English class to study the level of the profession.

Question 2: What kind of English application ability do you want to improve from the follow-up courses?

\section{A listening and speaking \\ $\mathrm{B}$ reading \\ C writing \\ D professional English}

In terms of language ability to improve, the highest level of attention is to improve listening and speaking ability, accounting for $74.5 \%$. When students have reached the basic requirement of the College English stage, they want to improve their ability to use language. The data also shows that most students have a correct understanding of the relationship between learning and examination.

Question 3: What are your requirements for the followup course?

\section{A last semester in grade three \\ B whole grade three \\ $\mathrm{C}$ the whole three or four grades semester \\ $\mathrm{D}$ second semester in grade two}

The survey shows that more than half of the students want to continue to learn English for four years so as to maintain their English level. There is a big gap between the students' demand and the current practice. In recent years, universities have been compressing college English classes and credits. Taking the level Four examination as the basic requirement of curriculum, students have formed the incorrect concept of "Learning College English has passed 
four levels". Some students want to further learn other English courses after they have passed college English test four levels, but schools do not necessarily set up relevant courses to meet students' needs, which lead to "disconnection" in English learning in the next two years.

Question 4: A curriculum mode(s) you want to follow?

\section{A traditional classrooms}

B ordinary multimedia classroom

\section{C phonetics Laboratory}

\section{D network autonomous learning center}

$72.2 \%$ of the surveyed students hope that the teaching mode of subsequent courses is combined with classroom instruction and autonomous learning, while only $6.8 \%$ of students like the mode of classroom teaching. Obviously, college students' autonomous learning will have been greatly improved and the traditional teaching mode has been challenged.

After statistical analysis of the feedback results of questionnaires, it is found that students have diverse, centralized and personalized elective contents of College English follow-up courses. $80 \%$ of the students reached a consensus that the school is necessary to open the English elective courses for those who have passed college English test four or six.

\section{REFLECTIONS ON THE SETTING UP OF SUBSEQUENT ELECTIVE COURSES}

The setting up of subsequent elective courses for College English should be designed in accordance with the principles of ESP. ESP is the transition from basic English to Applied English. It is neither a mere language course nor a professional course, but a combination of language application and professional knowledge. When designing, we should give full consideration to the language foundation of the teaching objects in English listening, speaking, reading and writing. We should consider three factors: Student's needs, teaching contents and teaching methods. At the same time, it advocates the teaching method of student-centered, a method of teacher's guidance and student study, a method of information reading and information exchange.

\section{A. Ideas for the Follow-up Course Design}

1) The curriculum design pattern of EGP + ESP: The basic design pattern of college English teaching can be assumed to be: EGP + ESP model. According to the new curriculum requirements, the study of the follow-up courses should belong to the improvement stage of college English. Therefore, EGP courses and ESP courses combine to try to open the bridge curriculum between general English and professional English. Content design of the follow-up courses not only has the characteristics of diversification and individuation, but also can meet the students' individual needs and social needs to ensure that different levels of students can be fully trained and improved in English application ability.

EGP + ESP teaching mode can be divided into two stages: the first stage is to complete the EGP study, with two to three semesters to complete. In the second stage-ESP elective courses, students who have passed college English four and six through four take English for specific purposes according to their actual needs with one to two semesters to complete. This model of curriculum design not only solves the contradiction between the normal teaching and the social needs of the people, but also fully excavates the students' interest.

2) Module teaching to meet the needs of different levels: Module teaching can meet the needs of different levels. According to the survey results, it can be divided into the following modules: module 1:to set up the subsequent application of professional English curriculum, such as news, tourism English, legal English, business letter writing, practical English writing. Module 2: continued courses offering practical skills, including senior oral English, listening comprehension, speaking, advanced writing. Module 3: continued courses providing cross-cultural knowledge such as introduction of western countries, cultural knowledge, ways of thinking, values, customs, history, comparative teaching Chinese and Western culture. Module 4: open appreciation curriculum, including movies, music, myth, fiction and poetry, etc.

3) Optimize the resources of teaching materials: Most of the current college English textbooks, from the text, vocabulary to exercises belong to the EGP category. And the appropriate ESP textbook is the smooth development of the follow-up courses. ESP materials should be selected with the actual needs of the students as the starting point, combined with different courses, different teaching objects, authentic and practical consideration teaching materials. A set of teaching materials of knowledge, interest, and practice is no doubt the common expectation between teachers and students. Therefore, we need to optimize the teaching material resources and adapt to the changing social development situation, so that teaching materials can help teachers organize classroom teaching and meet the needs of students and society. On the premise of teaching principals, teachers should be encouraged to choose their own materials and constantly optimize the teaching resources. Teachers should also collect the material closely related to the students' specialty, and combine the curriculum learning with the social needs to improve the students' ability to use the language in a comprehensive way.

\section{CONCLUSION}

First, the demand analysis will help to build a scientific and reasonable follow-up course system, train the talents to meet the needs of the society, and optimize the knowledge structure of the talents. The ultimate aim of foreign language teaching is to cultivate qualified foreign language talents suitable for social needs. The follow-up course is an effective 
way to improve the English comprehensive ability, and is the guarantee to meet the students' future employment and their own development. In view of the diversity and complexity of the teaching objectives of the follow-up course, it is more necessary to conduct in-depth social and personal needs analysis in the course of setting up the curriculum.

Finally, the demand analysis is helpful to improve the teaching effect. The development of the follow - up curriculum based on demand analysis is a teaching method of "learner- centered", which is put forward by the humanistic education view. First of all, through the analysis of demand, teachers can have a better understanding of the concept of the learners' desire and gap. Secondly, through the analysis of demand, students can participate in the curriculum decision-making. On the one hand, the courses can better meet their wishes and needs. On the other hand, analysis of demand is a reflection of learning methods and learning target. It can make it clearer to understand the purpose of the study and methods of their own.

\section{REFERENCES}

[1] Leaver,B.L. \& S.B.Stryker . Content-based instruction for foreign language classrooms [J]. Foreign Language Annals, 1989(3).

[2] Cai Jigang. Research on the basis and Countermeasures of post College English Teaching Reform [J]. Foreign language electrification Teaching, 2010 (3).

[3] Guo Jianjing. Research on the teaching of Specific English [M]. Beijing: Intellectual Property Rights Edition society, 2012.

[4] Higher Education Department of the Ministry of education. Teaching requirements for College English Course [M]. Shanghai:Shanghai foreign language education press, 2007.

[5] $\mathrm{Li} \mathrm{Li}$, Li Qingxin. A questionnaire survey on the setting up of the four level curriculum for College English Discussion [J]. New Curriculum Research, 2010 (2).

[6] Xia Jimei. The quality view of the practice of modern foreign language teaching materials -- on Modern Foreign Language Teaching Teacher training function of wood [J]. Foreign Language Circle, 2002 (2).

[7] Yuan Pinghua. The theoretical basis and teaching of foreign language teaching based on the content of the curriculum Meta model inquiry [J]. Degree and Graduate Education, 2006 (3). 